\title{
Long-term outcomes of pediatric hypospadias and surgical intervention
}

This article was published in the following Dove Press journal:

Pediatric Health, Medicine and Therapeutics

16 October 2012

Number of times this article has been viewed

\section{Gunter De Win ${ }^{1,2}$ \\ Peter Cuckow ${ }^{3}$ \\ Piet Hoebeke ${ }^{4}$ \\ Dan Wood ${ }^{2}$}

'Adolescent and Pediatric Urology, University Hospital, Antwerp, Belgium;

${ }^{2}$ Adolescent Urology, University

College London Hospitals, UK;

${ }^{3}$ Pediatric Urology, Great Ormond

Street Hospital for Sick Children,

London, UK; ' ${ }^{4}$ Pediatric Urology,

University Hospital, Gent, Belgium
Correspondence: Dan Wood

Adolescent Urology, University College

London Hospital, 250 Euston Road,

London NWI 2PG, UK

Tel +442034479422

Fax +442073809064

Email dan.wood@uclh.nhs.uk
Abstract: Hypospadias is one of the most commonly diagnosed male congenital disorders. Many surgical techniques are described and complications often reported include fistula, wound dehiscence, and meatal stenosis. Many surgeons still believe that hypospadias should be surgically corrected before the age of 12 months. However, it is clear that the longer the follow up, the more complications are reported. Correction of a failed hypospadias repair in adult patients can be challenging. While the need for repair of proximal hypospadias during childhood is evident, distal repair during childhood is questionable. Evidence suggests that the psychosexual and functional outcomes of nonoperated distal hypospadias in the adult population are good. Therefore, the benefit of surgery and the burden of complications must be carefully evaluated. This paper highlights the difficulties inherent in decisions related to the assessment of hypospadias, the need for repair, and the paucity of good long-term data.

Keywords: hypospadias, chordee, urethroplasty, fistula, stricture, hypospadias complications

\section{What is hypospadias?}

Hypospadias occurs in 1/300 to $1 / 250$ live male births ${ }^{1}$ and there has been a documented increase in its incidence, especially in developed countries. ${ }^{2-5}$ The underlying defect is the incomplete tubularization of the urethral folds during embryonic development. Its etiology is unknown, however genetic, developmental, endocrine, and environmental factors are probably involved in its pathogenesis.

The classic hypospadias triad consists of a proximal and ventrally positioned urethral meatus, a dorsal hooded foreskin, and ventral chordee (see Figure 1).

The position of the urethral meatus can be classified as distal (glandular, coronal, or subcoronal, $60 \%$ to $65 \%$ of cases), middle (midpenile, $20 \%$ to $30 \%$ of cases), or posterior or proximal (posterior penile, penoscrotal, scrotal, or perineal, $10 \%$ to $15 \%$ of cases). ${ }^{6}$

Recent data confirm that meatal position alone is not a reliable measure of severity ${ }^{7}$ (see Figure 2). The meatus may appear distal, but with poor quality underlying spongiosum and skin, reconstruction may require the urethra to be opened to healthy tissue, converting a distal appearance to a proximal problem. ${ }^{1}$ Therefore, the proximity of corpus spongiosum division is a better indicator of severity, combined with the quality of the urethral plate, degree of penile curvature and glanular size. ${ }^{7,8}$ Some would rather remove subjective terms such as "severity" from discussion and formulate a more objective terminology - this has yet to be done. ${ }^{8,9}$

It remains true that assessment can only be completed during operative dissection when it becomes clear where the spongiosum splits and the quality of the urethral plate is apparent. ${ }^{7}$ 


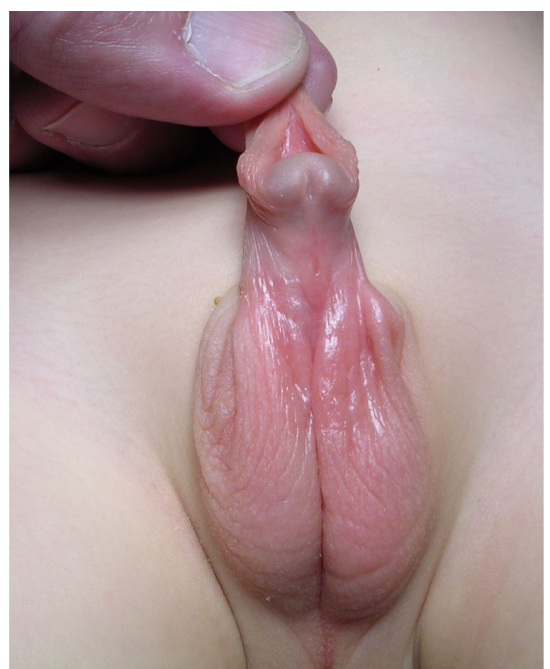

Figure I Hypospadias showing meatus on penile shaft and incomplete or hooded foreskin.

\section{Techniques and timing of hypospadias surgery}

The surgical goals of hypospadias repair are based on three key factors:

- terminalization of the meatus, to allow urination in a standing position and natural insemination,

- a straight penis, and

- good cosmesis.

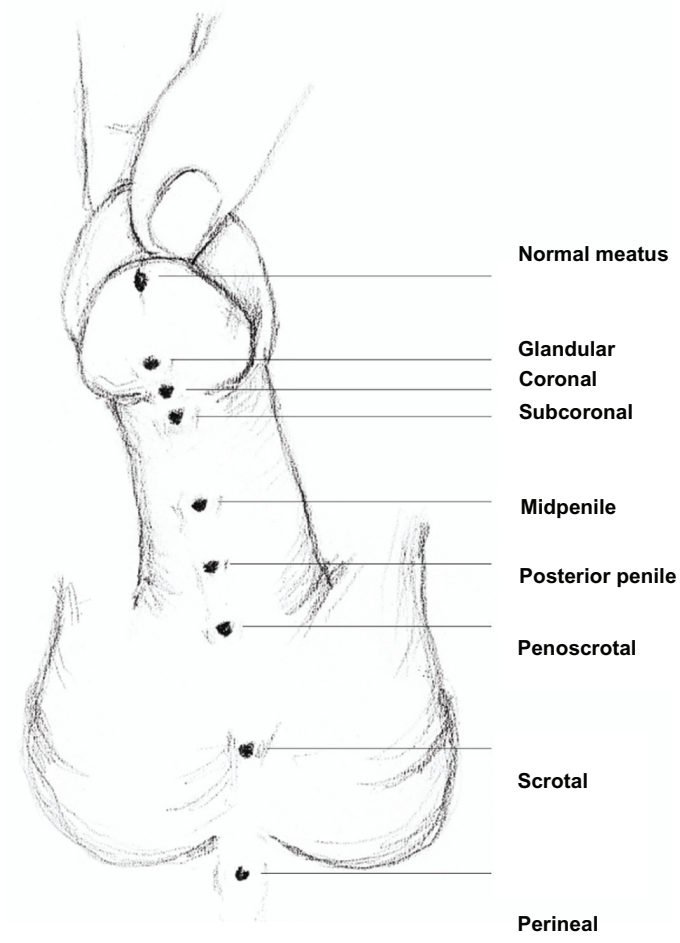

Figure 2 Classification of hypospadias based purely on meatal position (Illustration Mathilde Solanet).
Many surgeons believe that hypospadias should be surgically corrected within the first 12 months of life, prior to genital awareness, which begins at around 18 months a view supported by the American Academy of Pediatrics. ${ }^{10}$ While this stance is widely purveyed and safe, it is not based on scientific evidence. ${ }^{1,11}$

More than 200 techniques to correct hypospadias are described in the literature. The surgery can be technically demanding and surgeons performing the procedure must have a range of techniques at their disposal, allowing them to provide the best possible surgical result based on their findings at operation. ${ }^{12,13}$ There have been some improvement in outcomes, particularly in the challenging urethroplasty component; the works of Mathieu, Asopa, Duckett, Snodgrass, and others have been widely discussed, acknowledged, and published for their technical innovations in this field. Well vascularized urethroplasties using pedicled preputial grafts, preservation of the urethral plate, and the use of free mucosal grafts have all contributed to the body of literature on this topic. Two-staged procedures using free graft, introduced by Cloutier and modified by Bracka, have also been widely adopted. ${ }^{14,15}$

The description of so many techniques for a single problem may suggest a number of things:

1. The continued quest for outcome improvement - the most laudible and for many the most likely motivation

2. A wide spectrum of disease requiring a variety of surgical solutions

3. The absence of long-term data to reinforce the success or failure of one technique over another

4. The absence of a unified working pattern, and therefore, poor recognition of the need for standardization

5. The surgical ego and the desire to create an eponymous technique.

A recent worldwide survey of pediatric urologists examined trends in hypospadias repair and showed the meatal advancement and glanuloplasty (MAGPI) procedure to be the most popular for glandular hypospadias with good appearance of the tissues and glans. In this survey, the tubularized incised plate (TIP) procedure, introduced by Snodgrass, is the technique of choice in distal forms of hypospadias with urethral plate and good glandular and adequate ventral tissue. The TIP procedure, although feasible, is not widely used for proximal hypospadias. A two-stage technique is currently more popular, especially when substitution urethroplasty is required ${ }^{16}$ (see Figure 3). 


\section{A}

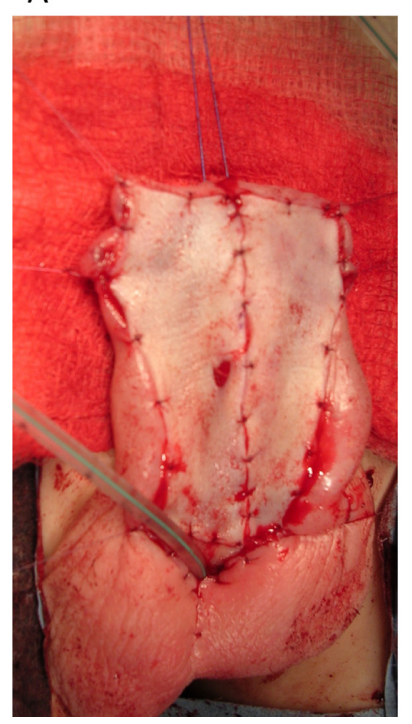

B

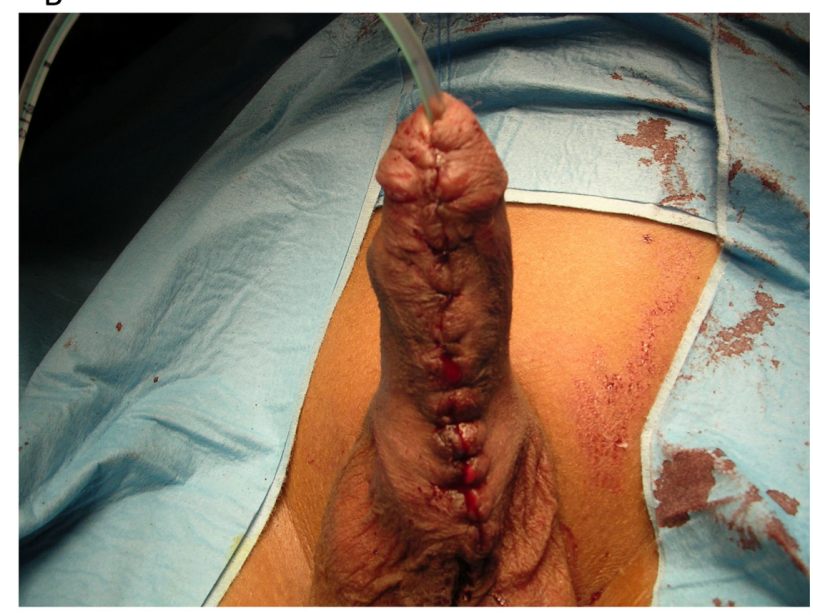

Figure 3 (A) Two skin grafts (in this case, two post-auricular Woolf grafts) applied to create a flat urethral plate - the first stage of a two-stage revision hypospadias repair. (B) End result of a two-stage repair.

\section{Long-term outcome of hypospadias repair: pediatric urology perspective}

The current literature reporting outcomes of hypospadias surgery is biased toward short-term or prepubertal outcomes. Complications range from $6 \%$ to $48 \%$, depending on the length of follow up (7 to 62 months) and the techniques used. ${ }^{12}$ Reliable data with follow up beyond adolescence are sparse. ${ }^{1}$

The heterogeneous patterns of both surgery and follow-up make data comparisons challenging. Thus, recommendations for surgical decision making, patient information, and outcome monitoring are extrapolated from a basis that is less than ideal. ${ }^{9,13}$

The most common recorded complications are poor cosmesis, fistulas, persistent chordee, urethral stricture, meatal stenosis, retrusive or proximal meatus, or glanular dehiscence (see Figure 4). ${ }^{1}$

Short-term outcomes might not reflect the long-term outcomes. Some recent large retrospective reviews suggest that complications continue to increase throughout puberty. Recently, Spinoit et a ${ }^{17}$ showed that the complication rate of $10 \%$ after 1 year increased to $25 \%$ during long-term follow up.

Furthermore, evaluation of hypospadias repair in prepubertal boys probably has limited bearing on outcomes in adult life; pubertal growth alone can change the final cosmetic appearance and function of the corrected penis. Furthermore, psychosexual development is not yet complete. It follows that long-term outcomes of hypospadias correction should be evaluated after puberty. ${ }^{18}$
Rynja et a $1^{18}$ recently reviewed all published series about long-term follow up of hypospadias repair in patients undergoing reconstruction at the age of 6 years and being at least 14 years of age at follow up. Only 19 studies were found, reporting 1027 patients of whom 180 had severe hypospadias. All studies showed a high loss to follow-up rate. The mean response rate of all these studies was $48.8 \%$. On average, patients were operated on 2.7 times.

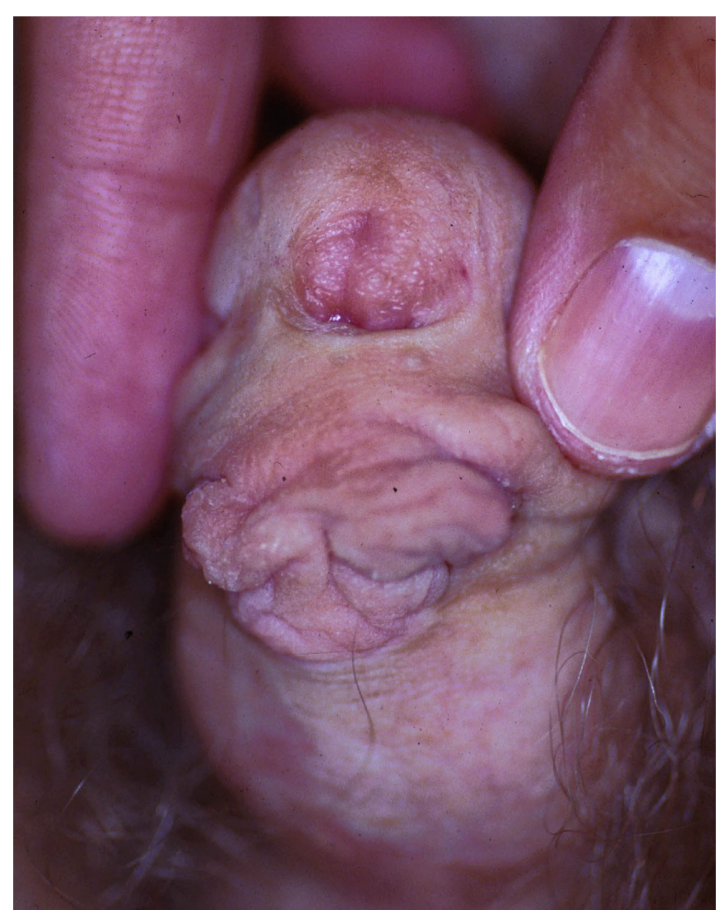

Figure 4 Failure of adult hypospadias repair. 
The results reported appear acceptable. Patients with hypospadias reported lower urinary tract symptoms twice as often, compared to controls, with dissatisfaction with urinary function, spraying, and deviation of the urinary stream being statistically significant. Objective assessment of cosmetic results was good; however, subjective satisfaction with penile appearance and penile length was lower in patients than in controls. ${ }^{18}$

Goyal et $\mathrm{al}^{19}$ reported on the long-term outcome of oral mucosa graft for hypospadias. Seventy percent of cases in this series were revisions. Most patients (81\%) received a single stage ventral onlay graft, $13 \%$ a urethral tube, and $6 \%$ a two-stage procedure. Twenty-seven percent had early complications, with a significantly higher rate in the urethral tube group. The majority of those having received oral mucosa grafts had stable outcomes at puberty. The authors recognized the late presentation of some complications, including meatal stenosis, and therefore, recommend periodic assessments until puberty, despite good initial outcomes.

There is limited literature examining the use of uroflowmetry for follow up of hypospadias patients. Additionally, the results of these tests are not always easy to understand. It is unclear whether an obstructed flow pattern is a result of hypospadias itself or of a lower first-pass maximum $\left(\mathrm{Q}_{\max }\right)$. In a study by Olsen et $\mathrm{al},,^{20} 31 \%$ of hypospadias infants appeared to have an obstructed flow pattern before surgery compared to none in the control group, but in a study by Wolffenbuttel et al, ${ }^{21}$ this proportion was only $6 \%$. Both studies used an ultrasound flow probe to measure the flow.

In 2004, Patel et al reported the long-term follow up of 30 patients from a cohort of 125 patients: 14 patients had undergone tubularized transverse island flap repair and $16 \mathrm{had}$ undergone onlay procedures. All patients in this follow up had normal urine flows, with all $\mathrm{Q}_{\max }$ values higher than the 95th percentile. ${ }^{22}$

Two studies compared two different hypospadias repair techniques and used the uroflow test as the outcome parameter. Scarpa et $\mathrm{al}^{23}$ observed more obstructive uroflows after TIP repairs than after Mathieu repairs (42\% vs $14 \%$ ) in distal hypospadias repair. Braga et al compared onlay repairs with TIP repairs for penoscrotal hypospadias. In the onlay group, $33.3 \%$ of patients had obstructed uroflow compared to $66.7 \%$ in the TIP group. ${ }^{24}$ These studies suggest that TIP repair is an obstructive technique. This is also seen in a study by Wolffenbuttel et al, ${ }^{21}$ where only $6 \%$ of patients had an obstructive uroflow before surgery; this rate increased to $41 \%$ during follow up.
However, Andersson et $\mathrm{al}^{25}$ recently published an article about uroflow and long-term follow up after TIP repair. Initially, after surgery, $49 \%$ of patients had a flow below the fifth percentile of the normogram, but after 7 years, this proportion was only $32 \%$. Therefore, they concluded that there is a high rate of spontaneous improvement in obstructive uroflow after surgery. Proximal hypospadias was more often related to an obstructive uroflow, and therefore, this study concluded that the use of TIP repair for proximal hypospadias should be limited. This conclusion is in line with the study by Braga. ${ }^{24}$

In a recent review about long-term outcomes, Rynja et al reported a $\mathrm{Q}_{\max }$ of $5-39 \mathrm{~mL} / \mathrm{s}$ in patients compared to $11.9-64.4 \mathrm{~mL} / \mathrm{s}$ in controls. ${ }^{18}$

González and Ludwikowski recently reviewed all articles about uroflow and hypospadias published between 1978 and $2011 .{ }^{26}$ In their study, they noticed that early obstructed uroflows improved spontaneously. Based on this review, they suggest a first test 1 year after surgery, around the age of potty training. Children with obstructed uroflow should be followed up more closely. However, the authors did not find any studies about follow up in asymptomatic patients with obstructive flows or with $Q_{\max }$ values below the fifth percentile. Therefore, the significance of this obstructed curve in asymptomatic children is not known.

Data supporting the durability of penile straightening procedures are lacking. Vandersteen and Husmann ${ }^{27}$ reported 22 cases of curvature more than 10 years after initial straightening. The median age of onset was 16 years (12-18 years). Therefore, the most critical point for curvature recurrence seems to be puberty, further underlining the need for long-term follow up.

In summary, these data suffer with a greater than $50 \%$ loss to follow up rate, wide case selection and technical variation, and a lack of validated measurement tools, making a realistic assessment all but impossible and emphasizing the need for standardized long-term, prospective data collection into adolescence and early adulthood.

\section{Psychosexual outcomes: patient perspective}

There is a body of literature comparing sexual outcome data in populations with hypospadias and control groups.

Patients with hypospadias express greater dissatisfaction with the cosmetic results of their surgery than circumcised patients $(33 \%$ vs $5 \%)$. Follow up of the patients with hypospadias was discontinued at a mean age of 7 years, 
whereas $40 \%$ of these patients would have preferred follow up to have been continued until the age of 15 to 18 years. ${ }^{28}$

Berg et $\mathrm{al}^{29}$ compared 34 postoperative hypospadias patients with 36 controls. They were interviewed about their sexual and social adjustment. The data showed that hypospadias patients had a tendency to be more withdrawn and socially isolated as adults. They had lower self-esteem and decreased capacity for social or emotional relationships.

Formation of body image and sexuality are an important part of adolescent development; it therefore seems important to understand outcomes relevant to this at the time of adolescence. $^{30}$

Vandendriessche et $\mathrm{al}^{30}$ demonstrated that boys operated on for hypospadias had a significantly lower score on the self-perception profile for adolescents but had normal social, psychosocial, and sexual development compared to the normal population. However, it is important to note that in this study, a significant amount of boys declined participation because of continuing consequences of hypospadias in their lives. Therefore, those at highest risk of psychosocial and sexual problems may have self-excluded from this study.

Other studies have given a different perspective. Shönbucher et $\mathrm{al}^{31}$ showed that boys with corrected hypospadias may show a psychosexual development similar to healthy children. This study suggested that the later corrective surgery was completed, the more likely patients were to be insecure with gender role behavior. This gender role behavior was not related to the degree of hypospadias - the inference is that the timing of surgery in relation to age, and possibly puberty, is important.

In a recent literature review, Rynja et $\mathrm{al}^{18}$ showed that hypospadias patients are as sexually active as controls, but less satisfied with sexual functioning and have intimate relationships less often. Outcomes were slightly worse with proximal hypospadias.

All the above mentioned studies compare operated hypospadias patients with the normal population. The data are somewhat inconclusive. It is also interesting to note that there have been population-based studies that have identified non-operated hypospadias without any apparent difficulty; these will be discussed later.

\section{Failed hypospadias repair: a reconstructive surgeon's perspective}

Where hypospadias has always been a core interest of pediatric urologists, nowadays, adult urologists subspecializing in urethral and penile reconstruction are becoming increasingly involved with the long-term complications of hypospadias. Although naturally skewed, these outcomes are an essential part of long-term follow up for hypospadias (and other congenital conditions treated in childhood).

Patients presenting to the reconstructive surgeon can be divided into two categories. One group of patients has ongoing problems such as fistulae, residual hypospadias penile curvature, and cosmetically unacceptable glanular or penile skin appearance. Some of these deformities may be perceived as being worse than the primary disease.

In the other group of patients, hypospadias surgery may fail many years after achieving initially successful functional and cosmetic results with primary repair. Urethral stricture may develop some time after initial hypospadias surgery. ${ }^{32}$ These patients present long after pediatric follow up has stopped and are a complex surgical challenge with an acknowledged high complication rate. ${ }^{33}$

A reliable rate of incidence of failed hypospadias in the adult population is unknown. Most adults with failed repair do not present to the pediatric urologist who first performed their surgery, which makes it difficult to calculate the real failure rate in adulthood.

In a recent analysis of 1776 patients with failed hypospadias repair, it was revealed that $16.4 \%$ of patients with failed repair had primary distal hypospadias and most patients underwent more than one operation to repair the primary defect. ${ }^{34}$ These data conflict with data reported by pediatric and plastic surgeons who suggest that most children are treated with a one-stage procedure with a high success rate, especially with distal disease.

In this study it was also seen that in patients who presented with penile strictures, $51 \%$ had failed hypospadias repair. ${ }^{34}$

There are a number of theories as to why strictures develop in adults previously treated for hypospadias, including: a scarred or poorly vascularized urethra that fails to grow adequately during adolescence; absence of the corpus spongiosum, which serves as a shock absorber during sexual activity; Balanitis xerotica obliterans is a major reason for penile strictures. Data are not clear as to whether those previously treated for hypospadias have a higher than expected incidence of this condition.

In some series, $25.5 \%$ of complications were only related to the urethra. ${ }^{33}$ Another complication is damage to the corpora cavernosa. The aesthetic appearance of 
the genitalia is also important. A collaborative approach including urethral surgeons and surgeons skilled in penile reconstructive surgery can ensure optimal cosmetic and functional outcomes. Among patients who presented with failed hypospadias repair, $13.4 \%$ required corpora cavernosa grafting to repair residual curvature.

The success rate of surgery for failed hypospadias repair when only the urethra was involved was $89.7 \%$; however, when multiple compartments had to be corrected, the success rate dropped to $79.5 \%$, even in an expert, high volume center. $^{33}$

Senkul et $\mathrm{al}^{35}$ reported a success rate of $72.5 \%$ in adult patients with failed hypospadias repair.

Data from these studies confirm that it is important to extend the follow up period beyond puberty to such time when genital maturation is complete. They highlight the need for long-term prospective data collection as there is a clear disparity between the short-term data presented by pediatric urology and that from adult centers. Both have significant and opposite biases; neither will answer the question in isolation.

\section{Outcome of untreated hypospadias}

Patients with marked chordee and a proximal urethral meatus will be significantly affected by their malformation. The functional impairment caused by milder variants of hypospadias may be less obvious.

A study by Fichtner et $\mathrm{al}^{36}$ found that in 500 consecutive men who underwent transurethral resection of the prostate or transurethral resection of a bladder tumor, only $55 \%$ of their study population's meatus was at the glans. Thirteen percent had subcoronal, coronal, or glanular hypospadias without any functional complaint; $63 \%$ of these patients were unaware of their genital anomaly.

Another prospective survey evaluating every male patient who came to a general urology practice (for various complaints: eg, stones, benign prostatic hypertension [BPH]) identified hypospadias in 56 adult patients having a mean age of 53 years. Only two of these patients had fertility problems. These two patients had unrelated oligospermia. Thirty-two percent of the patients were not aware they had hypospadias. One of these patients had a meatus in the distal third of the penile shaft. Another $11 \%$ were only aware that they had hypospadias because somebody had told them. Of these 56 , nine had undergone surgery for hypospadias as a child, and still did not have a meatus at the "normal" position; six had multiple operations as a child; and only one patient presented with a complaint related to hypospadias.
Ninety-five percent had been sexually active without any difficulty, two patients (18 and 20 years of age) reported they had not had a sexual partner. ${ }^{37}$

The mean age in both studies ${ }^{36,37}$ was rather high and the data cannot be regarded as exhaustive. They do suggest that foregoing surgery for distal hypospadias is a safe and reasonable option. There is no clarity about body image issues or sexual function in young adulthood and it cannot be assumed that all was well, but both studies suggest that normal relationships and urinary function are achievable in this group.

The Cleveland Clinic published their series ${ }^{38}$ on adult hypospadias patients with complaints related to the condition. The mean age at presentation was 37 years. Patients were divided into three groups: those who had undergone multiple surgeries for repair with significant scarring and tissue loss, those with delayed complications after an initially successful childhood repair, and those who had not undergone repair. None of the patients in the last group $(n=7)$ reported psychological sequelae relating to the cosmesis of their uncorrected hypospadias. Voiding difficulties were the major complaints in this group but this seemed to be related to balanitis xerotica obliterans. Four of the seven patients were also found to have an incidental chordee (this was not one of their presenting complaints). Although the study group with nonoperated hypospadias was small and the authors did not explain the degree of uncorrected hypospadias, these patients did not seem to suffer as a result of hypospadias or a lack of surgery. ${ }^{38}$

In a recent worldwide review about current practice in hypospadias repair, only $12 \%$ of pediatric surgeons were in favor of "no correction" for glanular hypospadias. ${ }^{17}$ In their discussions on whether or not to operate on distal hypospadias, it was thought that extrinsic factors, such as the views of the parents, might be more important than the actual appearance of the penis. ${ }^{37}$ Most parents want their son's penis to look as normal as possible. Pediatric surgeons have to deal with parents' expectations and that makes the decision to operate or not to operate much more difficult.

\section{Delayed repair}

The vast majority of literature about hypospadias relates to treatment in childhood, however, several publications about repair in adulthood are available. Almost all these papers report increased postoperative complications.

Due to the cosmetic nature of distal repair, some surgeons suggest delaying them until adolescence. An older patient has greater awareness of his condition and is able to make 
independent decisions. However, some reports suggest a worse outcome when hypospadias is repaired at a later age. Until the psychological outcome of nonoperated hypospadias during adolescence is known, this will remain a difficult issue to deal with.

Hensle et $\mathrm{al}^{39}$ published a $52.3 \%$ complication rate for hypospadias repair in 42 adults and $75 \%$ complication rate in cases where buccal mucosa was used. The majority of patients in this study underwent multiple repairs in childhood. For the ones who underwent primary repair in adulthood, the complication rate was $37.5 \%$. However, these data show that whether primary repair in adulthood or treatment for late complications, a high failure rate needs to be anticipated. This may be because the surgery is technically demanding, it may be disease-related, or studies not concentrated at single centers may suggest problems with low-volume surgeons.

Secrest et $\mathrm{al}^{40}$ reported 190 adolescent and adult cases with an average age at surgery of 16 years. The overall success rate was high (94.4\%), but low in 53 patients where urethral reconstruction was performed (45\%). It is important to understand that hypospadias repair without urethral reconstruction is only possible in the most distal cases, where surgery has be regarded as principally cosmetic rather than functional. The difficulty is that if functional complications occur, a cosmetic problem has been converted into a functional one.

Senkul et $\mathrm{al}^{35}$ also found a higher complication rate when hypospadias was repaired in adulthood and significantly more of the patients required multiple interventions. The mean age in his group was 21.9 years. The complication rate for the primary repairs was $10.1 \%$, and $27.5 \%$ for the recorrections. It should be noted that 14 of the 59 patients in the primary repair group only had MAGPI repair.

Marocco et $\mathrm{al}^{41}$ noted an increased number of complications in children older than 1 year compared to patients younger than 1 year of age (18.7\% vs 3.4\%).

The reasons for this higher complication rate in older patients remain unclear. They could include the difference in wound healing, postoperative erection, or differences in vascularity, but there is little evidence to support any single hypothesis.

However, when revision hypospadias surgery is compared with an age-matched adult cohort analysis with urethroplasty for other indications, no difference in complication rate was found. ${ }^{42}$

\section{Discussion}

The initial outcome in most pediatric series for different types of hypospadias repair is good. However, the longer the follow up, the more complications are reported. A typical period for late failures is adolescence, suggesting the importance of pubertal development in determining a true outcome picture. However, many patients with complications presenting in adolescence tend not to present to pediatric urologists. Adult reconstructive urologists are important in informing the pediatric urology community of late failures. However, due to a lack of prospective long-term follow up, the actual late complication rate is unknown.

Therefore, long-term prospective data collection is urgently needed, but very difficult to obtain. This prospective follow up needs to be continued into early adulthood, at least. A reduction in variation of hypospadias assessment and improved standardization of surgical techniques - as is possible in a high volume center - is necessary to derive a true complication rate. Collaborations between different high volume centers and adolescent or reconstructive urologists will be vital in achieving this.

For proximal hypospadias, there is no doubt that correction of the malformation is functionally important. The necessity for surgical repair of distal hypospadias without chordee remains controversial.

The degree of childhood penile curvature that will inhibit sexual intercourse in adulthood or the long-term psychosexual outcome in these patients remains unknown. ${ }^{8}$

Data show little functional impact on non-operated adults with hypospadias; this needs to be balanced against the potential for complications if repair is undertaken. However, there is no evidence to support any psychosexual effects during growth and adolescence.

Following surgery, not all minor complications seen after doing hypospadias repair warrant an additional operation to make the anatomy "perfect." Meatal caliber rather than position are more likely to be significant with symptoms such as spraying of the urinary stream. The more operations done to completely reposition the meatus, the greater the risk of scarring and further symptoms, as supported by the increasing complication rates seen in published series for revision hypospadias repair.

Indications for revision of hypospadias surgery in the adult population include: a recurrent curvature, poor cosmesis, urethral obstruction, or fistula.

The complexity of some cases may benefit from a combined surgical approach between andrologists and adult urethral surgeons.

In summary, to date, the reports on the outcome of hypospadias repair are sparse, and results of prospective studies with long-term follow up are still lacking. 
Functional and cosmetic outcomes are generally assessed in a subjective manner. Standardization of these assessments seems to be increasingly important. ${ }^{8}$

Studies comparing the sexual functional or psychological adaption and outcomes of patients who were successfully operated on for hypospadias with a control group of similarly affected, but untreated, individuals would be extraordinarily difficult to achieve, but would be of immense value.

\section{Disclosure}

The authors report no conflict of interest in this work.

\section{References}

1. Baskin LS, Ebbers MB. Hypospadias: anatomy, etiology, and technique B. J Pediatr Surg. 2006;41:463-472.

2. Paulozzi LJ, Erickson JD, Jackson RJ. Hypospadias trends in two US surveillance systems. Pediatrics. 1997;100(5):831-834.

3. Dolk H. Rise in prevalence of hypospadias. Lancet. 1998;351(9105): 770 .

4. Pierik FH, Burdorf A, Nijman JMR, et al. A high hypospadias rate in The Netherlands. Hum Reprod. 2002;17(4):1112-1115.

5. Lund L, Engebjerg MC, Pedersen L, et al. Prevalence of hypospadias in Danish boys: a longitudinal study, 1977-2005. Eur Urol. 2009;55(5): 1022-1026.

6. Leung AKC, Robson WLM. Hypospadias: an update. Asian J Androl. 2007;9(1):16-22.

7. Snodgrass W, Macedo A, Hoebeke P, Mouriquand PDE, Paolo S. Hypospadias dilemmas: A round table. J Pediatr Urol. 2011;7(2): $145-157$.

8. Giannantoni A. Hypospadias classification and repair: The riddle of the Sphinx. Eur Urol. 2011;60(6):1190-1191; discussion 1191-1192.

9. Snodgrass W. Hypospadias reporting - How good is the literature? JURO. 2010;184(4):1255-1256.

10. Timing of elective surgery on the genitalia of male children with particular reference to the risks, benefits, and psychological effects of surgery and anesthesia. American Academy of Pediatrics. Pediatrics. 1996;97(4):590-594.

11. Weber DM, Schonbucher VB, Gobet R, Gerber A, Landolt MA. Is there an ideal age for hypospadias repair? A pilot study. J Pediatr Urol. 2009; 5(5):345-350.

12. Snodgrass W, Bush N. Tubularized incised plate proximal hypospadias repair: Continued evolution and extended applications. J Pediatr Urol. 2011;7(1):2-9.

13. Castagnetti M, El-ghoneimi A. Surgical management of primary severe hypospadias in children: systematic 20-year review. JURO. 2010; 184(4):1469-1475.

14. Cloutier AM. A method for hypospadias repair. Plast Reconstr Surg Transplant Bull. 1962;30:368-373.

15. Bracka A. Hypospadias repair: the two-stage alternative. Br J Urol. 1995;76 Suppl 3:31-41.

16. Springer A, Krois W, Horcher E. Trends in hypospadias surgery: results of a worldwide survey. Eur Urol. 2011;60(6):1184-1189.

17. Spinoit AF, Poelaert F, Van Laecke E, Groen LA, Hoebeke P. Hypospadias in a single reference centre: long-term follow-up is mandatory to detect the real complication rate. Abstract S9-4; 23rd ESPU meeting. May 2012.

18. Rynja SP, de Jong TPVM, Bosch JLHR, de Kort LMO. Functional, cosmetic and psychosexual results in adult men who underwent hypospadias correction in childhood. J Pediatr Urol. 2011;7(5):504-515.

19. Goyal A, Singh MVA, Dickson AP. Oral mucosa graft for repair of hypospadias: outcomes at puberty. JURO. 2010;184(6):2504-2509.
20. Olsen LH, Grothe I, Rawashdeh YF, Munch T. Urinary flow patterns in infants with distal hypospadias. J Pediatr Urol. 2011;7(4):428-432.

21. Wolffenbuttel KP, Wondergem N, Hoefnagels JJS, et al. Abnormal urine flow in boys with distal hypospadias before and after correction. J Urol. 2006;176(4 Pt 2):1733-1736; discussion 1736-1737.

22. Patel RP, Shukla AR, Snyder HM. The island tube and island onlay hypospadias repairs offer excellent long-term outcomes: a 14-year follow-up. J Urol. 2004;172(4 Pt 2):1717-1719; discussion 1719.

23. Scarpa MG, Castagnetti M, Berrettini A, Rigamonti W, Musi L. Urinary function after Snodgrass repair of distal hypospadias: comparison with the Mathieu repair. Pediatr Surg Int. 2010;26(5):519-522.

24. Braga LHP, Pippi Salle JL, Lorenzo AJ, et al. Comparative analysis of tubularized incised plate versus onlay island flap urethroplasty for penoscrotal hypospadias. J Urol. 2007;178(4 Pt 1):1451-1456; discussion 1456-1457.

25. Andersson M, Doroszkiewicz M, Arfwidsson C, Abrahamsson K, Holmdahl G. Hypospadias repair with tubularized incised plate: Does the obstructive flow pattern resolve spontaneously? J Pediatr Urol. 2011;7(4):441-445.

26. González R, Ludwikowski BM. Importance of urinary flow studies after hypospadias repair: a systematic review. Int J Urol. 2011;18(11): 757-761.

27. Vandersteen DR, Husmann DA. Late onset recurrent penile chordee after successful correction at hypospadias repair. J Urol. 1998;160(3 Pt 2): 1131-1133; discussion 1137.

28. Aho MO, Tammela OK, Somppi EM, Tammela TL. Sexual and social life of men operated in childhood for hypospadias and phimosis. A comparative study. Euro Urol. 2000;37(1):95-100; discussion 101.

29. Berg R, Svensson J, Aström G. Social and sexual adjustment of men operated for hypospadias during childhood: a controlled study. $J$ Urol. 1981;125(3):313-317.

30. Vandendriessche S, Baeyens D, Van Hoecke E, Indekeu A, Hoebeke P. Body image and sexuality in adolescents after hypospadias surgery. J Pediatr Urol. 2010;6(1):54-59.

31. Schönbucher VB, Landolt Ma, Gobet R, Weber DM. Psychosexual development of children and adolescents with hypospadias. J Sex Med. 2008;5(6):1365-1373.

32. Barbagli G, De Angelis M, Palminteri E, Lazzeri M. Failed hypospadias repair presenting in adults. Euro Urol. 2006;49(5):887-894; discussion 895 .

33. Perovic S, Barbagli G, Djinovic R, et al. Surgical challenge in patients who underwent failed hypospadias repair: is it time to change? Urol Int. 2010;85(4):427-435.

34. Barbagli G, Perovic S, Djinovic R, Sansalone S, Lazzeri M. Retrospective descriptive analysis of 1,176 patients with failed hypospadias repair. J Urol. 2010;183(1):207-211.

35. Senkul T, Karademir K, Işeri C neyt, et al. Hypospadias in adults. Urology. 2002;60(6):1059-1062.

36. Fichtner J, Mottrie AM, Hohenfellner R. Analysis of meatal location in 500 men: wide variation questions need for meatal advancement in all pediatric anterior hypospadias cases. J Urol. 1995;154:833-834.

37. Dodds PR, Batter SJ, Shield DE, et al. Adaptation of adults to uncorrected hypospadias. Urology. 2008;71(4):682-685; discussion 685.

38. Ching CB, Wood HM, Ross JH, Gao T, Angermeier KW. The Cleveland Clinic experience with adult hypospadias patients undergoing repair: their presentation and a new classification system. BJU Int. 2011;107(7): $1142-1146$.

39. Hensle TW, Tennenbaum SY, Reiley EA, Pollard J. Hypospadias repair in adults: adventures and misadventures. $J$ Urol. 2001;165(1):77-79.

40. Secrest CL, Jordan GH, Winslow BH, et al. Repair of the complications of hypospadias surgery. J Urol. 1993;150(5 Pt 1):1415-1418.

41. Marrocco G, Vallasciani S, Fiocca G, Calisti A. Hypospadias surgery: a 10-year review. Pediatr Surg Int. 2004;20(3):200-203.

42. Lumen N, Hoebeke P, Deschepper E, et al. Urethroplasty for failed hypospadias repair: a matched cohort analysis. J Pediatr Urol. 2011; $7(2): 170-173$ 
Pediatric Health, Medicine and Therapeutics

Dovepress

\section{Publish your work in this journal}

Pediatric Health, Medicine and Therapeutics is an international, peerreviewed, open access journal publishing original research, reports, editorials, reviews and commentaries. All aspects of health maintenance preventative measures and disease treatment interventions are addressed within the journal. Practitioners from all disciplines are invited to submit

Submit your manuscript here: http://www.dovepress.com/pediatric-health-medicine-and-therapeutics-journal their work as well as healthcare researchers and patient support groups. The manuscript management system is completely online and includes a very quick and fair peer-review system. Visit http://www.dovepress. $\mathrm{com} /$ testimonials.php to read real quotes from published authors. 